\title{
Improved Mixing and Sampling Systems for Vitrification Melter Feeds
}

Topical Report
January 1998

\author{
By: \\ M. A. Ebadian
}

RECEIVED

OCT 261998

OSTI

Work Performed Under Contract No.: DE-FG21-95EW55094

For

U.S. Department of Energy

Office of Fossil Energy

Federal Energy Technology Center

P.O. Box 880

Morgantown, West Virginia 26507-0880

\section{MASTEP}

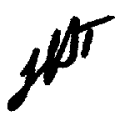

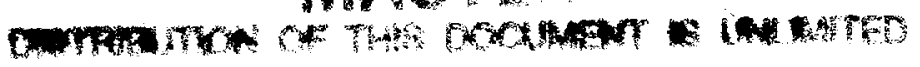

By

Florida International University

Hemispheric Center for Environmental Technology (HCET)

Center for Engineering \& Applied Sciences

10555 West Flagler Street

EAS-2100

Miami, Florida 33174 


\section{Disclaimer}

This report was prepared as an account of work sponsored by an agency of the United States Government. Neither the United States Government nor any agency thereof, nor any of their employees, makes any warranty, express or implied, or assumes any legal liability or responsibility for the accuracy, completeness, or usefulness of any information, apparatus, product, or process disclosed, or represents that its use would not infringe privately owed rights. Reference herein to any specific commercial product, process, or service by trade name, trademark, manufacturer, or otherwise does not necessarily constitute or imply its endorsement, recommendation, or favoring by the United States Government or any agency thereof. The views and opinions of authors expressed herein do not necessarily state or reflect those of the United States Government or any agency thereof. 


\section{DISCLAIMER}

Portions of this document may be illegible in electronic image products. Images are produced from the best available original document. 
This report is based on work supported by the U. S. Department of Energy (DOE), Office of Environmental Management, Office of Science and Technology's Tank Focus Area. The Principal Investigator, Florida International University Collaborator, and students at Florida International University would like to thank DOE for providing us the opportunity to work on this project. 


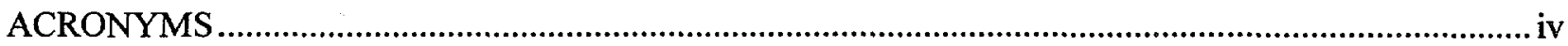

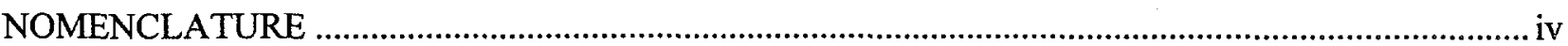

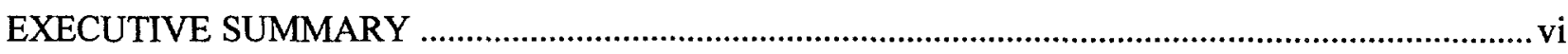

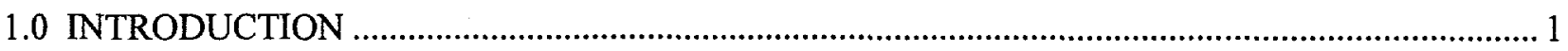

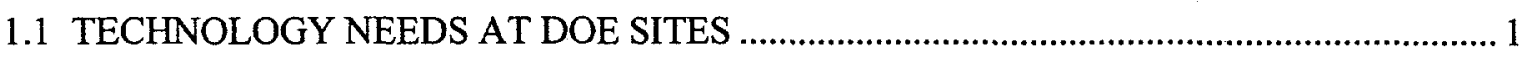

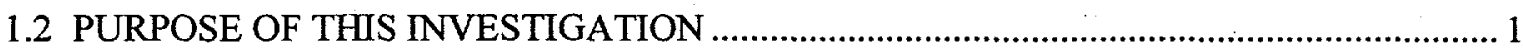

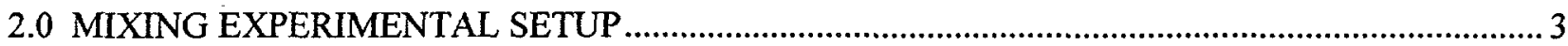

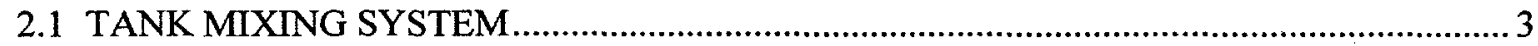

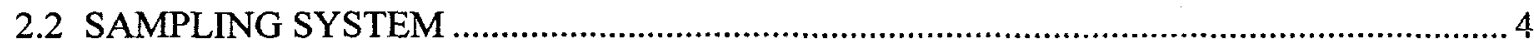

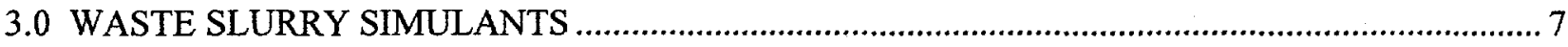

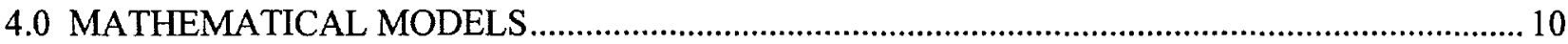

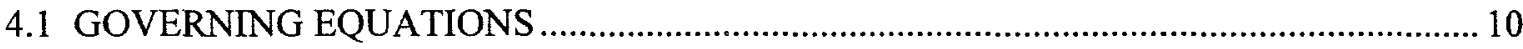

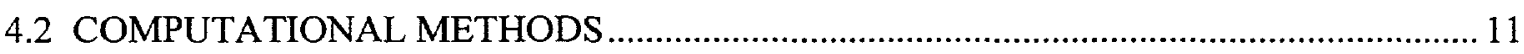

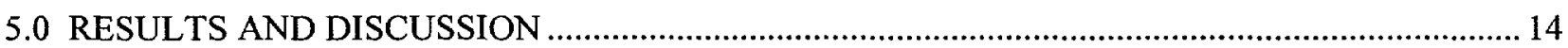

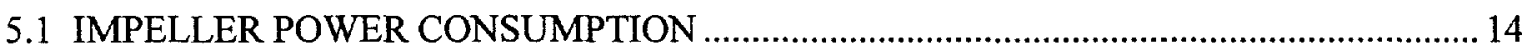

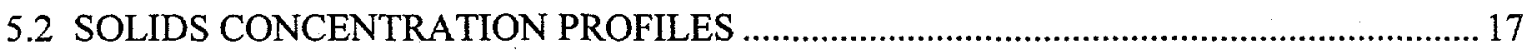

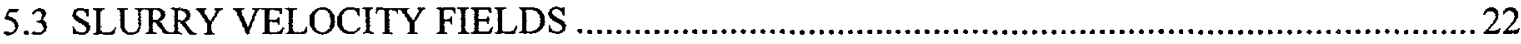

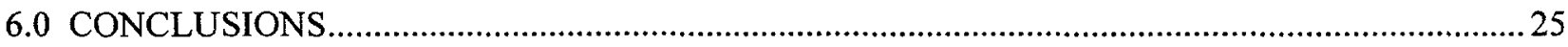

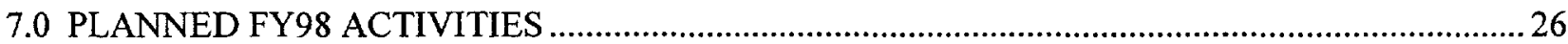

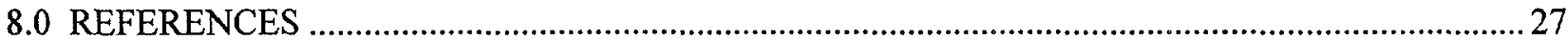




\section{ACRONYMS}

CFD computational fluid dynamics

DOE U.S. Department of Energy

DWPF Defense Waste Processing Facility

FIU Florida International University

FIU-HCET - Florida International University-Hemispheric Center for Environmental Technology

FY97 fiscal year 1997

FY98 fiscal year 1998

HCET Hemispheric Center for Environmental Technology

SRS Savannah River Site

\section{NOMENCLATURE}

c

volumetric solids concentration

D

diameter of impeller or mixing tank

$\mathrm{H}$

height

ID

inner diameter

LH

liquid height

LV

tank volume

$\mathrm{N}$

impeller speed

$\mathrm{N}_{\mathrm{Re}}$

Reynolds number

$\mathrm{Np}$

Power number

$\mathrm{u}$

velocity

$\mathrm{p}$

pressure

$P$

power consumption

$r$

radial direction

$\mathrm{x}, \mathrm{y}, \mathrm{z}$

rectangular coordinate system

$\alpha$

solids volume fractions

$\rho$

density 


\section{Subscripts}

$\begin{array}{ll}\mathrm{i}, \mathrm{j}, \mathrm{k} & \text { spatial indication } \\ \mathrm{f} & \text { fluid } \\ \mathrm{s} & \text { solid }\end{array}$


This report summarizes the methods used and results obtained during the progress of the study of waste slurry mixing and sampling systems during fiscal year 1997 (FY97) at the Hemispheric Center for Environmental Technology (HCET) at Florida International University (FIU). The objective of this work is to determine optimal mixing configurations and operating conditions as well as improved sampling technology for defense waste processing facility (DWPF) waste melter feeds at U.S. Department of Energy (DOE) sites.

Most of the research on this project was performed experimentally by using a tank mixing configuration with different rotating impellers. The slurry simulants for the experiments were prepared in-house based on the properties of the DOE sites' typical waste slurries. A sampling system was designed to withdraw slurry from the mixing tank. To obtain insight into the waste mixing process, the slurry flow in the mixing tank was also simulated numerically by applying computational fluid dynamics (CFD) methods. The major parameters investigated in both the experimental and numerical studies included power consumption of mixer, mixing time to reach slurry uniformity, slurry type, solids concentration, impeller type, impeller size, impeller rotating speed, sampling tube size, and sampling velocities.

Application of the results to the DWPF melter feed preparation process will enhance and modify the technical base for designing slurry transportation equipment and pipeline systems. These results will also serve as an important reference for improving waste slurry mixing performance and melter operating conditions. These factors will contribute to an increase in the capability of the vitrification process and the quality of the waste glass. 


\subsection{INTRODUCTION}

\subsection{TECHNOLOGY NEEDS AT DOE SITES}

A slurry-fed melter is used in the vitrification process to treat high-level waste by the immobilization of radioactive elements in a durable glass waste form. This technology has been demonstrated and implemented by the DWPF at the DOE's Savannah River Site (SRS). The key to the successful vitrification of nuclear waste is mixing the waste slurry with glass additives to produce uniform chemical and physical properties. While the DWPF mixing and sampling systems for the melter feeds are operational, significant improvements in the understanding of waste slurry rheology and in the design of agitation and sampling systems have occurred since these were conceived in the early 1980s. In order to enhance and optimize the design and operation of the melter feed preparation process, refined and reliable data on the mixing and sampling system have to be obtained based on both laboratory-scale and simulated in-situ operating conditions.

A literature survey by the authors also shows that although there have been extensive studies on the regular mixing process in different industries, for example, those by Mei et al. (1997), NasrEl-Din et al. (1996), Rasteiro et al. (1994), MacTaggart et al. (1993), Gumby (1990), Magelli et al. (1990), Barresi and Baldi (1987), Yamazaki et al. (1986), Tojo and Miyanami (1982), and Herndl and Mersmann (1981), very few studies are currently available that are aimed at the application of slurry mixing and sampling in the DWPF vitrification melter feeds. The results on the regular mixing process in industries can be used as reference data for DWPF, but in most of the cases those results cannot be scaled to meet the requirements at DOE sites. This lack of information motivated us to conduct systematic study of the mixing and sampling process for the DWPF vitrification melter feeds.

\subsection{PURPOSE OF THIS INVESTIGATION}

In this investigation, experimental and theoretical studies have been performed to determine optimal mixing configurations and operating conditions as well as an improved sampling technology for DWPF waste melter feeds. The major objective of this work is to couple the practical knowledge and theoretical understanding resulting from this investigation with the experience derived from initial operation at DOE sites to modify equipment design and enhance the performance of the vitrification process.

The primary goals of enhancing the mixing of solid and liquid components in the slurry are to achieve uniformity and promote mass and heat transfer during the dissolution and heating processes. As chemical reactions and flocculation processes occur in mixing tanks and pipelines, optimal mixing can initiate these processes and assist their speedy completion. For the agitation of low-viscosity particle suspensions such as waste slurry, a variety of other physical and chemical process functions are carried out in vessels stirred by rotating impellers. To monitor the quality of the mixing process, proper sampling techniques must be used. 
In the experimental investigation, the mixing configuration of the stirring vessel (tank) with rotating impellers is emphasized. Slurry simulants used for all experiments were prepared and examined at FIU-HCET. An experimental facility has been set up and validated, and different agitation equipment has been tested to determine the optimal mixing system. Experimental cases with different operating conditions and sampling processes have been performed.

In the theoretical investigation, mathematical models for the three-dimensional slurry flows in the mixing tank have been developed. The slurry flows in the mixing tank have been modeled and simulated using CFD methods.

The following is a list of the major factors investigated in this experimental and numerical study:

- Effects of slurry concentration

- Effects of slurry type

- Effects of impeller rotating speed

- Effects of impeller size

- Effects of impeller type

- Effects of sampling tube size

- Effects of sampling velocity

Application of these experimental and modeling results to the DWPF melter feed preparation process will enhance and modify the technical base for designing slurry transportation equipment and pipeline systems. These results will also serve as an important reference for improving waste slurry mixing performance and melter operating conditions. These factors will contribute to an increase in the ability to perform the vitrification process and the quality of the waste glass. 


\subsection{MIXING EXPERIMENTAL SETUP}

\subsection{TANK MIXING SYSTEM}

Figure 1 presents a schematic representation of the overall physical arrangement of the system to be set up in the mixing laboratory. With this experimental system, slurry can be transferred from one tank to another by pumps. The slurry mixing process can take place in any single tank or in two of the tanks at the same time.

All the tanks used in this study were cylindrical and were made of high-density polyethylene. The dimensions (inside diameter (ID) $\times$ height ) of the the 30 -gal and 15-gal tanks are 18 in. $\times 30$ in. and 13 in. $\times 27$ in., respectively. All the slurry transport pipelines were constructed with 1 -in. stainless steel pipe. The slurry pump was provided by Power and Pumps Inc., Fort Lauderdale, Florida.

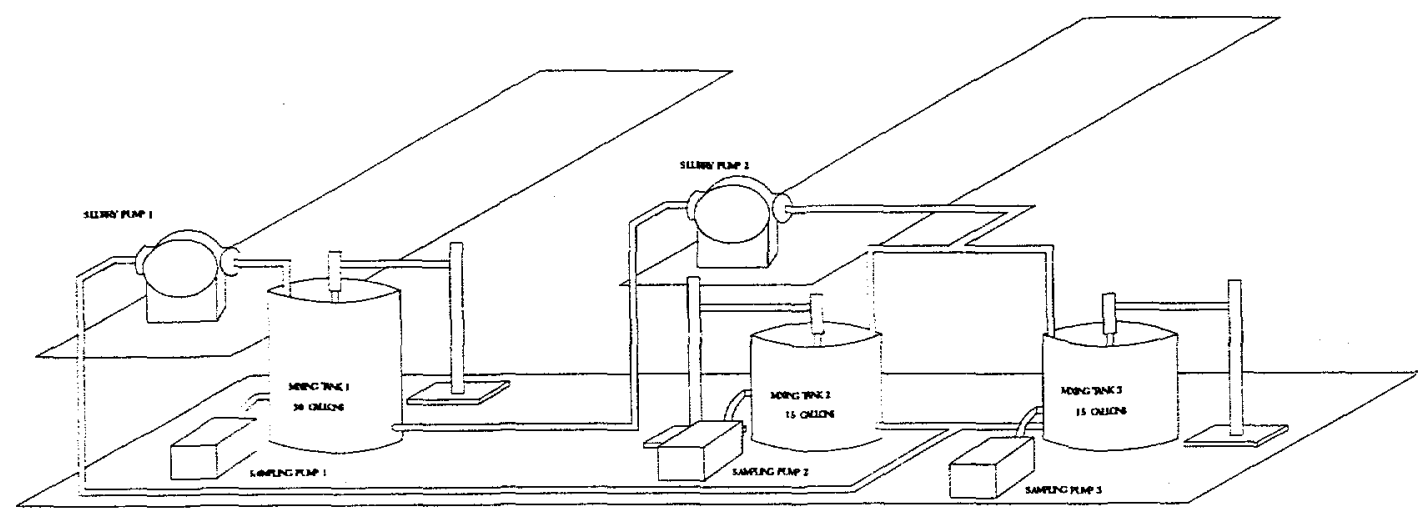

Figure 1. Distribution of the equipment in the experimental setup.

Figure 2 provides detailed experimental setup for measurement of the slurry mixing process in a tank. To ensure the symmetrical mixing, the shaft axis of the mixer is in line with the tank's vertical center line. Several removable baffles were attached to the wall of the tank to enhance the mixing process in the tank. This experimental system was able to run both transient (timedependent) and steady (time-independent) slurry mixing processes at various bulk solids concentrations. The major components of this tank mixing experimental setup include:

1) A $1 / 4$-horsepower (HP) electric motor, which was connected to the mixer and directly drove the mixer (impeller)

2) A wattmeter, which was used to record the power consumption of the mixer during the experiments

3) A remote optical sensor (LED) together with a digital display panel, which were used to measure the mixer's rotational speed 
4) A sampling system, which was designed to withdraw slurry from the mixing tank. The sampling system will be explained in detail in the next section.

The electric motor was supported by a carefully designed firm frame to reduce the mechanical vibration produced by the motor's rotational momentum. The frame was also used to change the relative height of the impeller in the mixing tank. The shaft and propeller of the mixer were made of stainless steel with a ratio of shaft length to shaft diameter of 36 in. to $3 / 4$ in. The operating range of the electric motor was 87 to $1750 \mathrm{rpm}$. In this study, two sets of propellers with up and down pump-flow directions were tested. Within each set of propellers, five different sizes of propeller were examined.
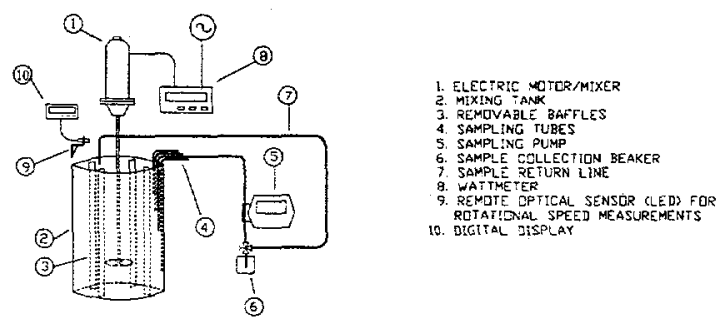

Figure 2. Tank mixing experimental setup.

During FY97, although research had been focused on the batch tank mixing process, some effort was also made to design a pipeline system to investigate the slurry mixing characteristics in transfer lines. The description of this pipeline system will be provided in next year's reports.

\subsection{SAMPLING SYSTEM}

As shown in Figure 2, the sampling system is one part of the entire tank mixing setup. During the experiments, the sampling system was operated simultaneously with other tank mixing process measurements. The sampling probes designed for this experimental study were straight circular tubes.

The sampling tube arrangement for the axial flow impeller in the mixing tank is shown in Figure 3. The sampling tubes were placed vertically inside the tank, with the inlet toward the bottom of the tank. This sampling system has at least three sampling tubes (probes) integrated together, with each one sliding inside the mixing tank at a different depth. As the position of the sampling tube is adjustable, this system allows sampling at different locations in both axial and radial directions inside the tank. 


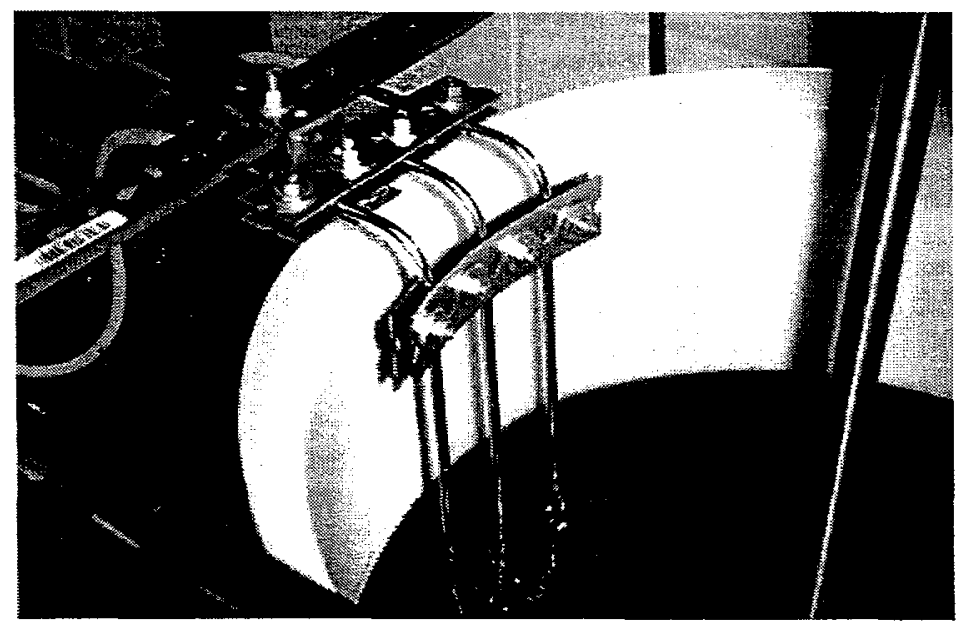

Figure 3. Sampling tube arrangement in the mixing tank for axial flow impeller. The sampling probes were straight tubes.

Figure 4 is a typical arrangement of sampling tubes in the mixing tank for radial flow impellers. The major difference between the design for a radial flow impeller and that for an axial flow impeller was the direction the probes were positioned inside the mixing tank. As shown in Figure 4 , the probes were situated perpendicularly toward the center line of the mixing tank. This could be achieved by using L-type tubes inside the mixing tank.

To demonstrate the possible influence of sampling tube scale, two sampling tube sizes (diameters) were used in this study. Each sampling tube is connected to a respective computercontrolled peristaltic pump (from Cole-Parmer), which is able to control the flow rate at which the samples are taken. When the impeller's rotational speed changes, the sampling flow rate must be adjusted to produce reliable results. Based on the slurry weight collected within a certain period of time, the sampling velocity can be determined. By drying the liquid in the collected slurry sample, the net solids weight and the slurry solids concentration can be obtained. 


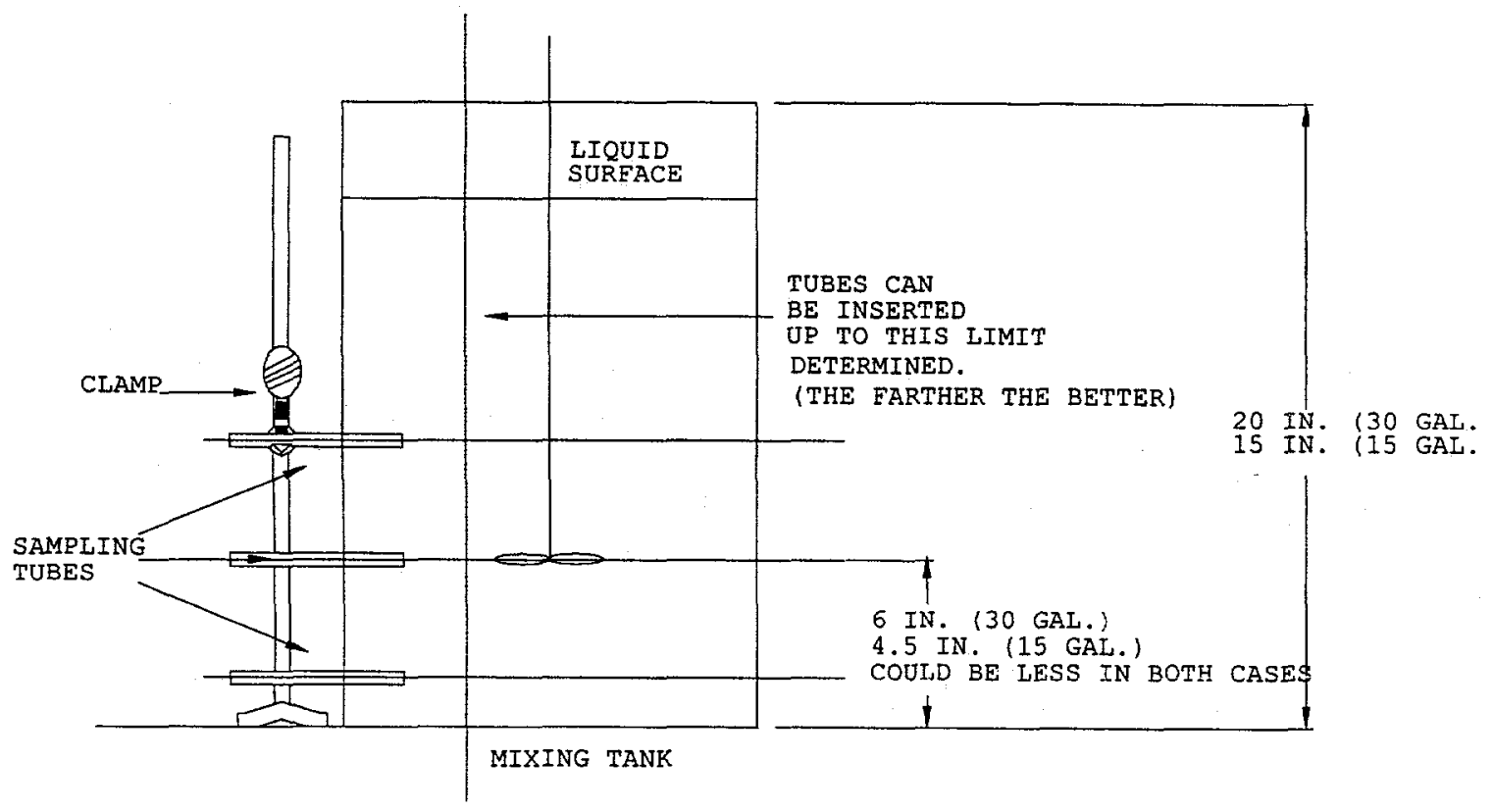

NOTES: 1. MORE THAN ONE SAMPLING TUBE CAN BE USED AT A TIME.

2. SAMPLING TUBES ARE MARKED SO THE DEPTH OF PENETRATION INSIDE THE TANK IS KNOWN.

Figure 4. Arrangement of sampling probes for radial flow impeller in the mixing tank. The sampling probes could be L-tubes. 


\subsection{WASTE SLURRY SIMULANTS}

Due to the difficulty of waste slurry delivery directly from DOE sites, the slurry simulants were prepared at FIU-HCET. The simulants prepared by using water and additives have similar properties to those used at DOE sites. The following major factors were considered when developing the slurry simulants: (a) solids concentration; (b) particle size; (c) slurry components; (d) $\mathrm{pH}$ value; and (e) shear viscosity.

Slurry I. This is the main slurry used for this project. Three of the most important components in the DWPF waste were selected for this simulant. Figure 5 shows the proportion of each compound in the slurry for a bulk solid concentration by weight of $5 \%$.

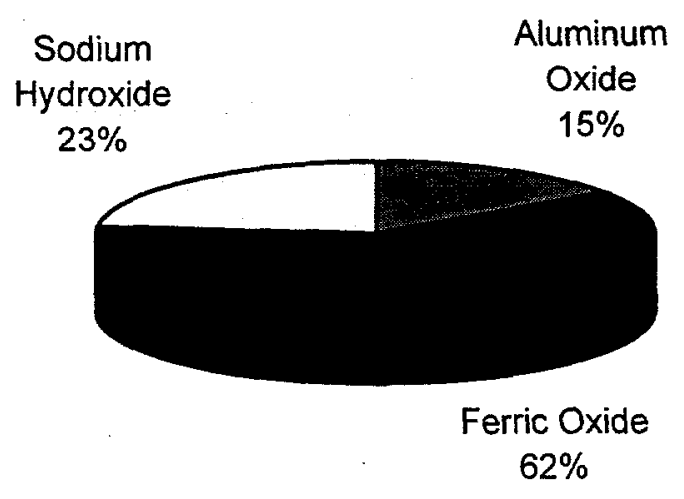

Figure 5. Proportion of each compound in the new slurry for a bulk solid concentration by weight of $5 \%$.

The particle size of the components used in slurry I was determined by using four sieves of different sizes. Table 1 presents the determined particle size range for ferric oxide powder $\left(\mathrm{Fe}_{2} \mathrm{O}_{3}\right)$, and Table 2 presents its corresponding average values. Tables 3 and 4 give the particle size ranges and average values, respectively, for aluminum oxide powder $\left(\mathrm{Al}_{2} \mathrm{O}_{3}\right)$. Because the sodium hydroxide dissolves completely in water, it does not constitute part of the solids in the slurry.

Table 1.

Particle Size Ranges for Ferric Oxide Powder in Slurry 1

\begin{tabular}{cc}
\hline $\begin{array}{c}\text { Particle Size Range } \\
(\mu \mathrm{m})\end{array}$ & $\begin{array}{c}\text { Percentage } \\
(\%)\end{array}$ \\
\hline $250-150$ & 0 \\
$150-75$ & 72.37 \\
$75-45$ & 22.09 \\
less than 45 & 5.54 \\
\hline
\end{tabular}


Table 2.

Average Particle Size of Ferric Oxide Powder in Slurry 1

\begin{tabular}{cc}
\hline $\begin{array}{c}\text { Average Particle Size } \\
(\mu \mathrm{m})\end{array}$ & $\begin{array}{c}\text { Percentage } \\
(\%)\end{array}$ \\
\hline 112.5 & 72.37 \\
60.5 & 22.09 \\
22.5 & 5.54 \\
\hline
\end{tabular}

Table 3.

Particle Size Ranges for Aluminum Oxide Powder in Slurry I

\begin{tabular}{cc}
$\begin{array}{c}\text { Particle Size Range } \\
(\mu \mathrm{m})\end{array}$ & $\begin{array}{c}\text { Percentage } \\
(\%)\end{array}$ \\
\hline $250-150$ & 0 \\
$150-75$ & 0.28 \\
$75-45$ & 24.15 \\
less than 45 & 75.57 \\
\hline
\end{tabular}

Table 4.

Average Particle Size of the Aluminum Oxide Powder in Slurry 1

\begin{tabular}{cc}
\hline $\begin{array}{c}\text { Average Particle Size } \\
(\mu \mathrm{m})\end{array}$ & $\begin{array}{c}\text { Percentage } \\
(\%)\end{array}$ \\
\hline 112.5 & 0.28 \\
60.5 & 24.15 \\
22.5 & 75.57 \\
\hline
\end{tabular}

Three samples of slurry I at bulk concentrations of 5\%, 20\%, and $40 \%$ by weight were prepared. It was determined that the $\mathrm{pH}$ value was 13 for all three samples. By means of a rotational viscometer, the apparent viscosity was measured with the same samples of slurries as used for $\mathrm{pH}$ value measurement. The viscosity values measured were $1 \mathrm{cP}$ for the $5 \%$ wt slurry, $9 \mathrm{cP}$ for the $20 \%$ wt slurry, and $1000 \mathrm{cP}$ for the $40 \%$ wt slurry. Based on the above measurements, the hindered settling velocities of the particles at concentrations of $5 \%, 20 \%$, and $40 \%$ by weight were calculated analytically. The obtained results were $0.013 \mathrm{~m} / \mathrm{s}, 0.0116 \mathrm{~m} / \mathrm{s}$, and $0.0087 \mathrm{~m} / \mathrm{s}$ for slurries at bulk concentrations of $5 \%, 20 \%$, and $40 \%$ by weight, respectively. 
Slurry II. This slurry simulant was prepared using only one additive-cerium oxide power. The average particle size is about $3.5 \mu \mathrm{m}$. The bulk concentration of slurry II used for the related experiments is $5 \%$ by weight. Slurry II was used basically as a backup of slurry I, especially for the impeller's power consumption measurements.

Slurry III. This slurry simulant was prepared from construction bricks with particle sizes less than $150 \mu \mathrm{m}$. Bulk concentrations of $1 \%$ and $1.85 \%$ by weight were examined for this slurry simulant. Slurry III was used primarily for testing runs of the batch tank mixing and sampling process. 


\subsection{MATHEMATICAL MODELS}

\subsection{GOVERNING EQUATIONS}

To obtain a good understanding of the physics in the tank mixing process, a reasonable granular multiphase model was proposed for the numerical simulation of the slurry mixing process in tanks. The solid phase stresses were derived by making an analogy between the random particle motion arising from particle-particle collisions and the thermal motion of molecules in a gas, taking into account the inelasticity of the granular phase. Using standard symbols, the general momentum equations for the primary (fluid) phase, $f$, and solid phase, $s$, are

$$
\begin{gathered}
\frac{\partial}{\partial}\left(\alpha_{f} \rho_{f} \vec{u}_{f}\right)+\nabla \cdot\left(\alpha_{f} \rho_{f} \vec{u}_{f} \otimes \vec{u}_{f}\right)=-\alpha_{f} \nabla p+\nabla \cdot \overline{\bar{\tau}}_{f}+\alpha_{f} \rho_{f} \vec{g}+ \\
\sum_{s=1}^{n}\left(K_{s f}\left(\vec{u}_{s}-\vec{u}_{f}\right)+\dot{m}_{s f} \vec{u}_{s f}\right)+\vec{F}_{f} \\
\frac{\partial}{\partial t}\left(\alpha_{s} \rho_{s} \vec{u}_{s}\right)+\nabla \cdot\left(\alpha_{s} \rho_{s} \vec{u}_{s} \otimes \vec{u}_{s}\right)=-\alpha_{s} \nabla p-\nabla p_{s}+\nabla \cdot \overline{\bar{\tau}}_{s}+\alpha_{s} \rho_{s} \vec{g}+ \\
\sum_{l=1}^{M}\left(K_{l s}\left(\vec{u}_{l}-\vec{u}_{s}\right)+\dot{m}_{l s} \vec{u}_{l s}\right)+\vec{F}_{s}+K_{f s}\left(\vec{u}_{f}-\vec{u}_{s}\right)+\dot{m}_{f s} \vec{u}_{f s}
\end{gathered}
$$

where $p_{S}$ is the solids pressure; $\alpha_{\mathrm{s}}$, the solids volume fractions; $g$, the acceleration due to gravity; $F$, additional momentum sources; $\tau$, stress-strain tensor; $K_{f s}=K_{S f}$, the fluid-solid momentum exchange coefficient; $K_{l s}$, the solid-solid momentum exchange coefficient between solid phases $l$ and $s$; and $M$, the total number of solids phases. In this study, the fluid-solid exchange coefficient, $K_{S f}$, and the solid-solid exchange coefficient, $K_{l s}$, have the forms derived by Syamlal et al. (1987 \& 1993). The collisional and kinetic parts are added to give the solids shear viscosity.

For slurry flows at high Reynolds numbers, the standard k- $\varepsilon$ two-equation turbulence model (Patankar and Spalding, 1972) was applied.

As per the literature researched, the steady state settling/dispersion model has proved to be fairly accurate for the prediction of solids distribution profiles in mixing tanks. The convectiondiffusion equation, resulting from the material balance in a control volume, is the starting point for the settling/dispersion modeling. Applied to a cylindrical container (e.g., our mixing tank) and thus, expressing it in cylindrical coordinates for convenience' sake, the equation can be written as follows:

$$
-\frac{\partial}{\partial y}\left(D_{i} \frac{\partial c}{\partial y}\right)-\frac{1}{r} \frac{\partial}{\partial r}\left(r D_{i} \frac{\partial c}{\partial r}\right)+\frac{\partial}{\partial y}\left(u_{i} c\right)+\frac{\partial}{\partial y}\left(u_{s} c\right)=0
$$


where the subscript $i$ refers to the different flow zones within the tank; $c$ denotes the volumetric concentration of solids; $D$ is the dispersion coefficient for each zone; $u_{i}$ represents the convective velocity; $u_{S}$, the settling velocity of the particles and $y$ and $r$, distances in the axial and radial directions, respectively.

\subsection{COMPUTATIONAL METHODS}

The slurry flows in the mixing tank were simulated by applying a CFD method. All the geometrical grids, physical models, and boundary conditions for the tank mixing process were generated or defined with software MixSim (from Fluent Inc.). The defined numerical models were solved by Fluent CFD software (from Fluent Inc.).

Figure 6 shows the typical geometrical parameters of 6-in. axial-flow impeller and stirring tank that were used in the present CFD simulation. Figures 7 and 8 demonstrate the outlines of the threedimensional grid generated with MixSim for the mixing tank. In this numerical study, a grid density of 40 , which was defined as the number of cells per diameter of mixing tank, was usually applied.

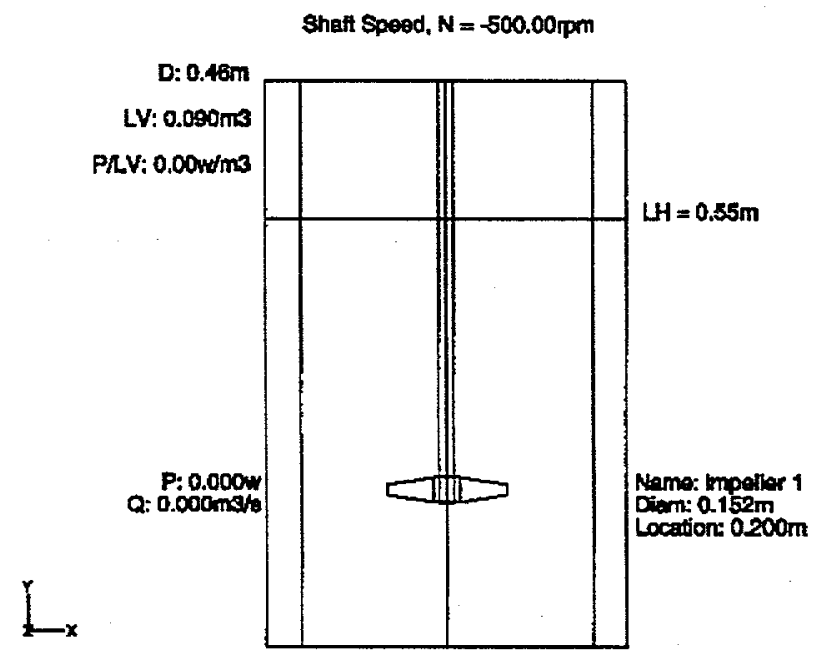

Figure 6. General geometrical parameters of a 6-in. axial-flow impeller and stirring tank used in the computational model. 


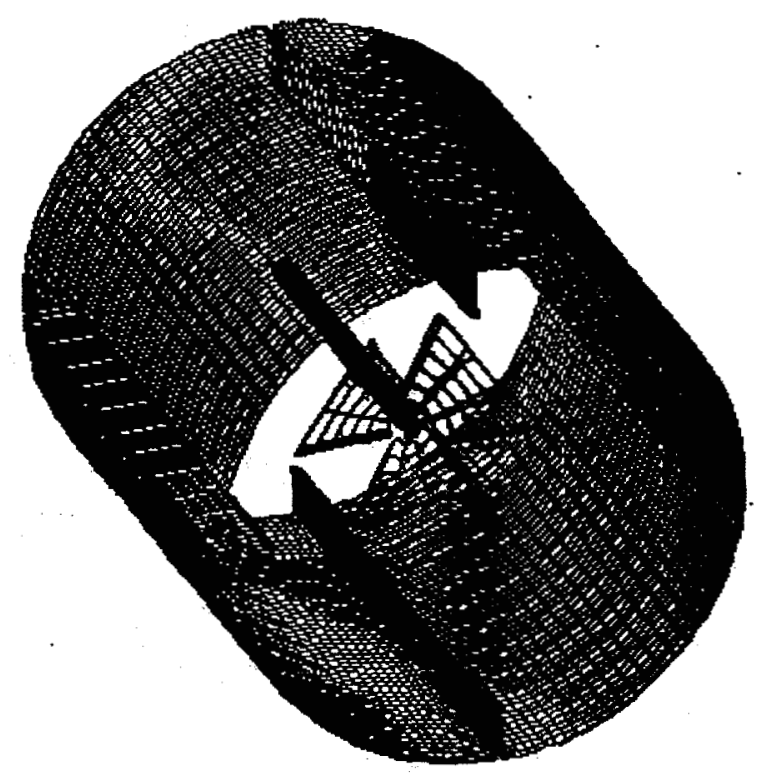

Figure 7. Three-dimensional grid used in the numerical model on impeller surface and on a circular section of the mixing tank.

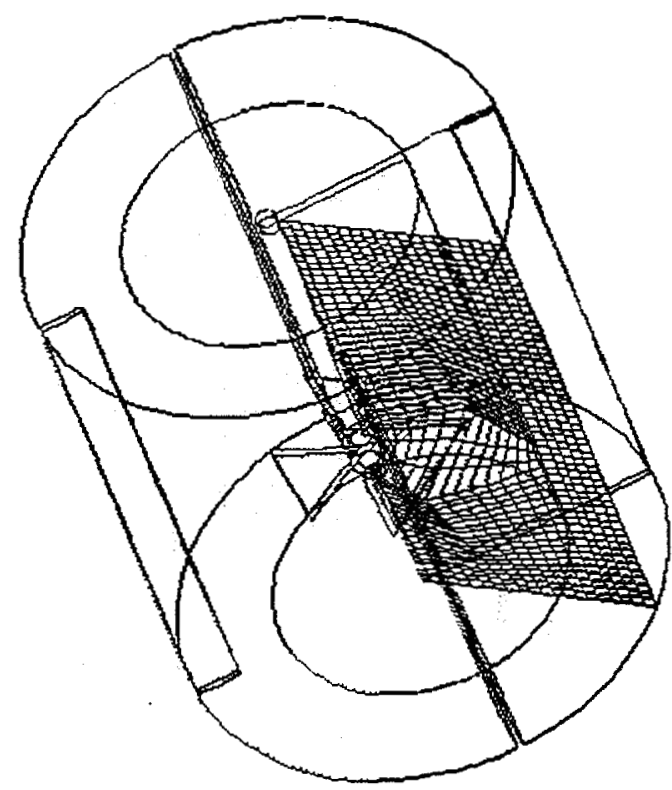

Figure 8. Grid used in the numerical model on a section between two adjacent baffles of the mixing tank. 
In the numerical simulation, the control volume finite differential method was used to solve the governing equations of the slurry flows in mixing tanks. The discretization schemes used for the velocity components and scalar variables were power-law interpolations. The SIMPLE algorithm by Patankar (1980) was used to resolve the coupling between velocity and pressure. The sliding mesh model was used for the three-dimensional baffled mixing tank simulations. The numerical computations were considered converged when the normalized residuals levels for all the variables had been reduced to no more than $10^{-3}$. All computations were performed on an SGI supercomputer at FIU-HCET. 


\subsection{RESULTS AND DISCUSSION}

\subsection{IMPELLER POWER CONSUMPTION}

To understand the relation between the impeller's power consumption at specific rotational speed and the characteristic fluid momentum in the mixing tank, an impeller power number $N_{P}$ and an impeller Reynolds number $\mathrm{N}_{\mathrm{Re}}$ were introduced:

$$
\begin{aligned}
& N_{\mathrm{Re}}=\frac{D^{2} N \rho}{\mu} \\
& N_{P}=\frac{P}{\rho N^{3} D^{5}}
\end{aligned}
$$

where $D$ denotes impeller diameter; $N$ is the impeller speed, and $P$ represents power $(N \mathrm{~m} / \mathrm{s})$. Some of the typical test calculations using the models are shown in Figures 9 and 10, where $\rho$ equals $1122 \mathrm{~kg} / \mathrm{m}^{3} ; \mu$ equals $0.5 \mathrm{~Pa}$. The relationship between the power number and Reynolds number represented in Figure 9 corresponds to impeller diameters of $3.5 \mathrm{in}$. The effect of impeller size on the power consumption at the same impeller Reynolds number is shown in Figure 10.

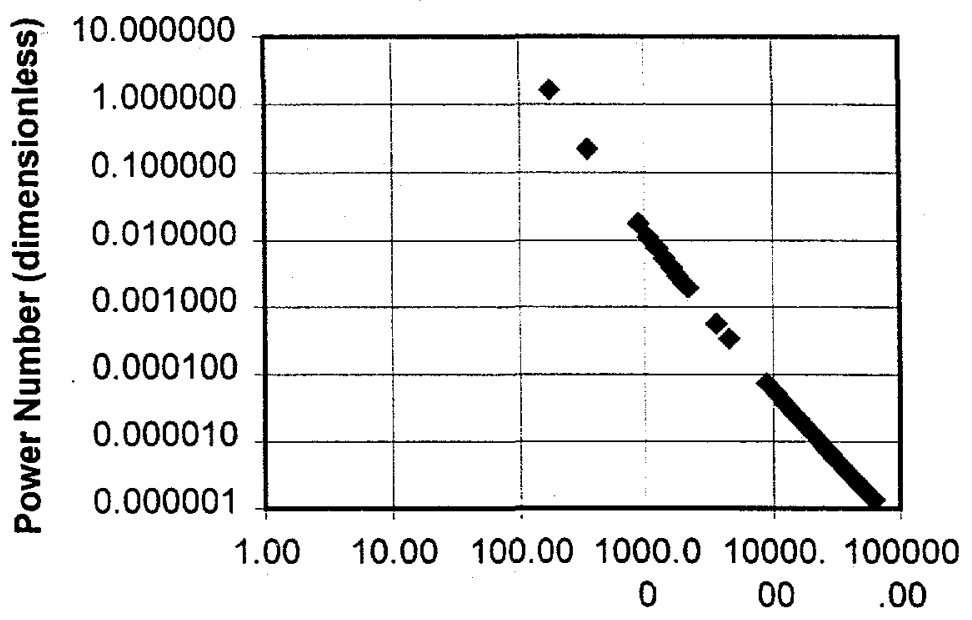

Impeller Reynolds Number (dimensionless)

Figure 9. Relationship between the power number and the Reynolds number for a propeller 3.5 in. in diameter (Di/Dt=0.26). 


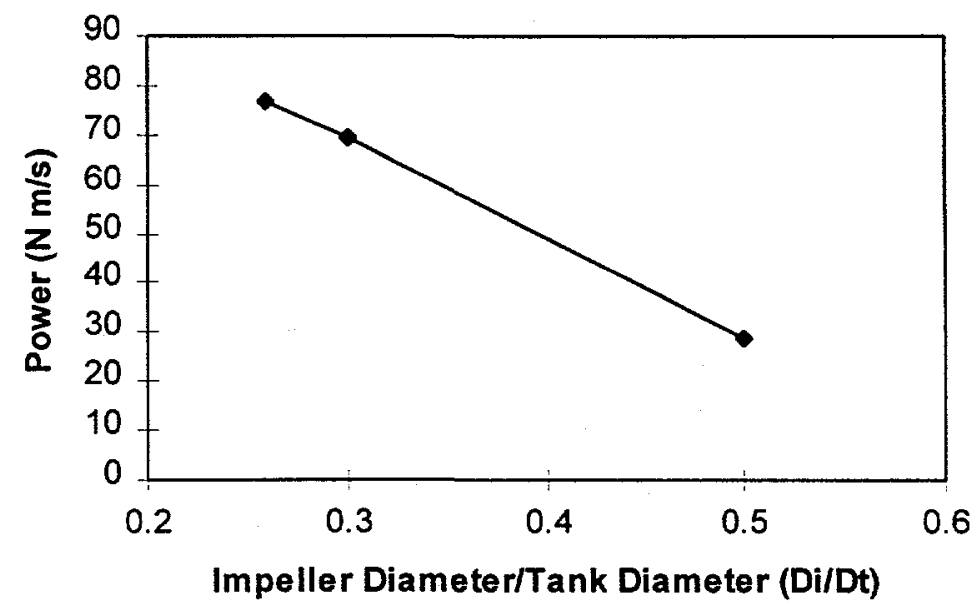

Figure 10. Relationship between power and the size of the impeller at a Reynolds number of 1200.

In the following, the power consumption characteristics were determined under steady state for five different sizes of two different types of axial-flow impellers, namely "flow-up" and "flowdown" impellers for slurry II of $5 \mathrm{wt} \%$ bulk concentrations. Figure 11 shows the electric power consumption of all five different sizes of axial-up-flow impellers used. Figure 12 presents the same comparison for the axial-down-flow impellers. It can be clearly observed that the bigger the impeller used, the more power is drawn by the motor. Although the weight of a bigger impeller might be a driving factor of the power consumed, the higher levels of turbulence produced plays an important role in the power consumption. The role of the impeller size in the performance of the mixing process under steady-state conditions is more evident when the curves of the 4-in. and the 8-in. impellers are compared. For instance, at a rotational speed of $500 \mathrm{rpm}$, the 8 -in. impeller provides much more turbulence (which is highly desirable for mixing purposes) than its 4-in. counterpart. On the other hand, the 8-in. impeller consumes approximately 5 times more electric power than the 4-in. impeller, which makes it much less cost-efficient.

In Figure 13, the power consumptions of a mixer with a 6-in. impeller are compared in water and a $5 \mathrm{wt} \%$ slurry II. It is expected that as the solids concentration of the slurry is increased, the difference in power consumption between the two media will be more dramatic.

The power consumption characteristics of the impeller with slurry I were also tested. It was found that slurry I has almost the same power consumption as slurry II under the same operating conditions. This indicates the possibility of using the same type or size of mixer to meet the requirements of different waste slurries at $\mathrm{DOE}$ sites. 


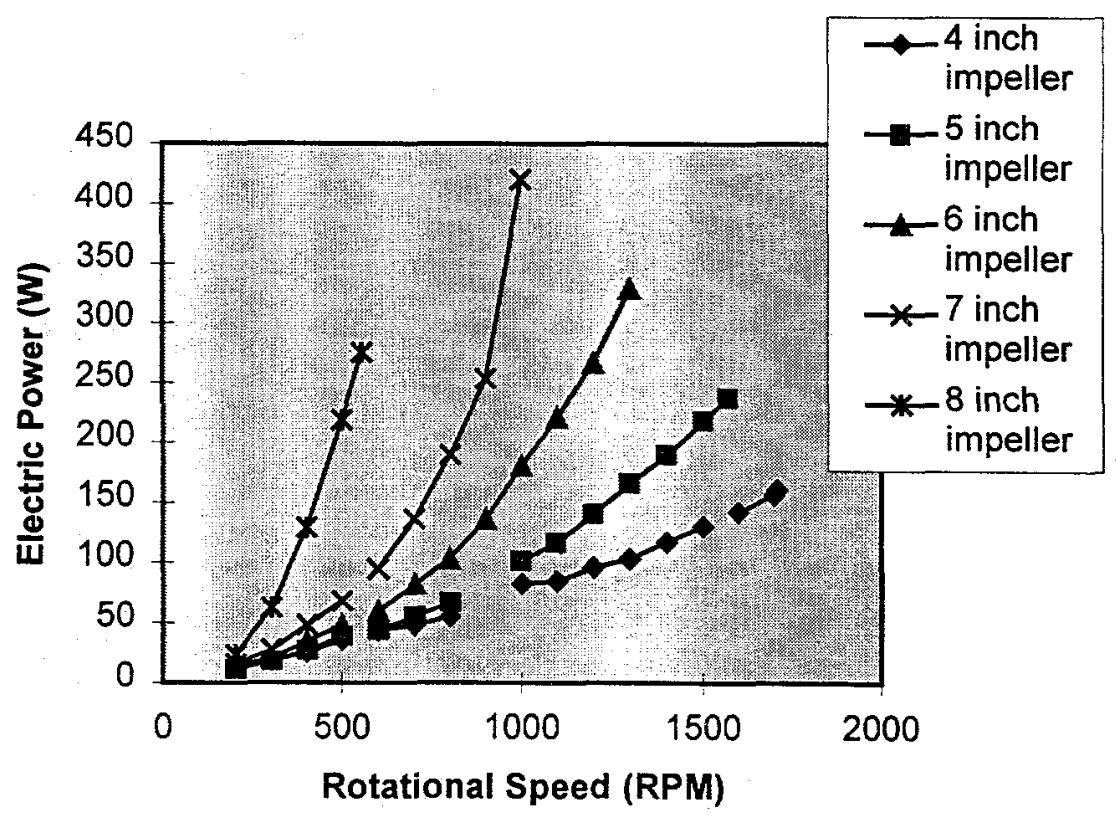

Figure 11. Electric power consumed vs. the rotational speed of the mixer using axial-down-flow impellers. Slurry is a water-cerium oxide powder mix at a concentration of $5 \mathrm{wt} \%$.

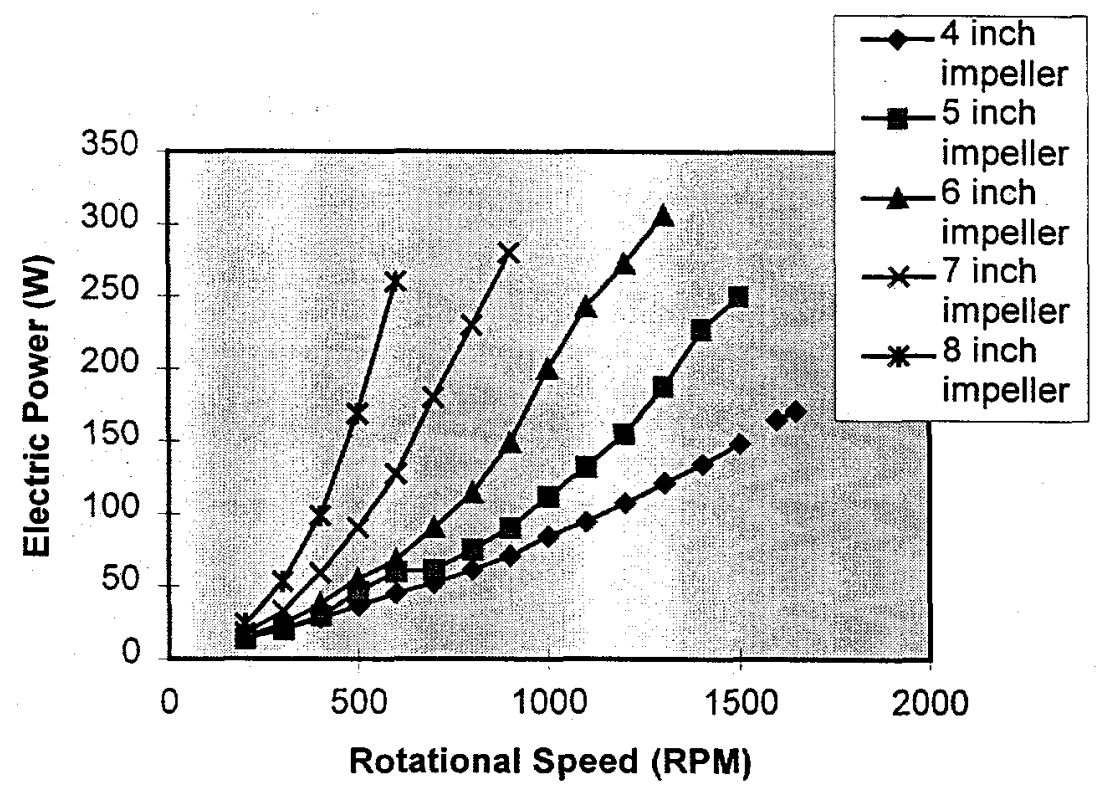

Figure 12. Electric power consumed vs. the rotational speed of the mixer using axial-up-flow impellers. Slurry is a water-cerium oxide powder mix at a concentration of 5 wt \%. 


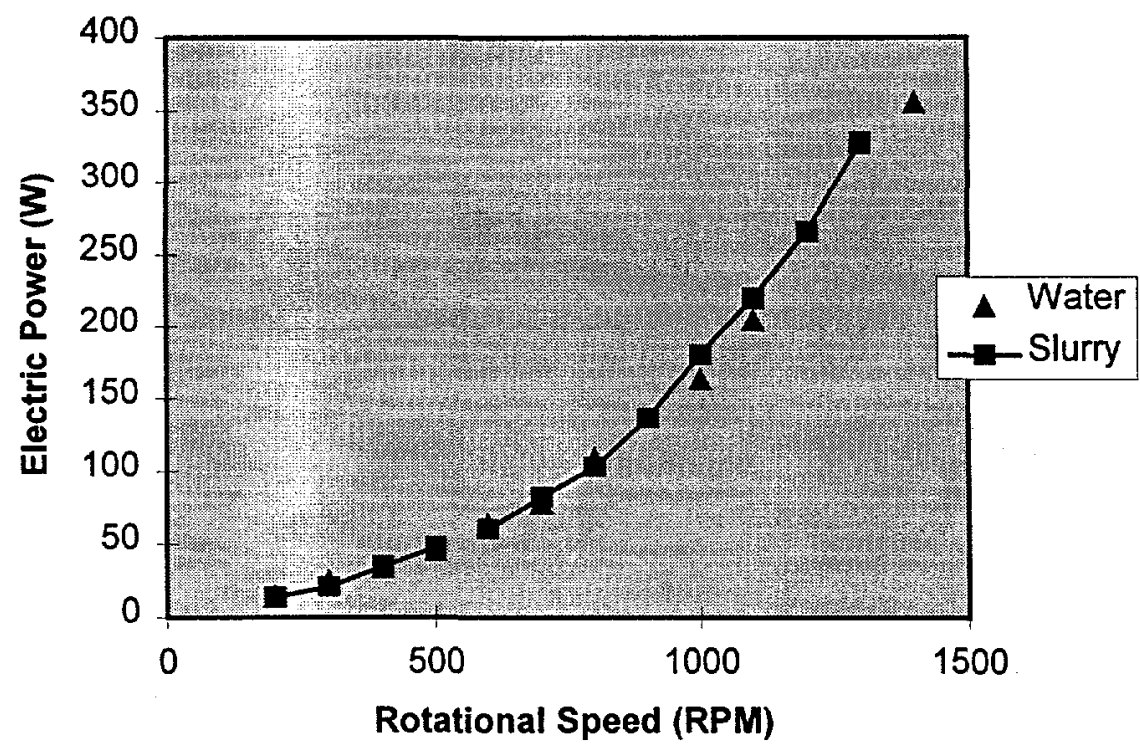

Figure 13. Electric power consumed vs. mixer rotational speed of a 6in. axial-down-flow impeller working on water and on a slurry of $5 \mathrm{wt}$ $\%$ concentration.

\subsection{SOLIDS CONCENTRATION PROFILES}

Experiments were performed to determine the mixing time, i.e., the time necessary to achieve an acceptable homogeneity in the slurry at different rotational speeds for a 4-in.-diameter impeller. The results reported here are those for slurry III. The experimental setup consisted of setting the mixer at a fixed rotational speed and taking samples of the slurry at different time intervals. Figure 14 presents a comparison between two different rotational speeds ( 300 and $1600 \mathrm{rpm}$ ) and illustrates the manner in which the axial concentration profile develops with time. The rotational speed of $1600 \mathrm{rpm}$ maintains the concentration at all three points along the tank axis fairly close to that of the average bulk concentration of the slurry $(1.85 \mathrm{wt} \%)$, while at a rotational speed of $300 \mathrm{rpm}$, the homogeneity begins to be lost at approximately 45 minutes. After an hour of continuous mixing at $300 \mathrm{rpm}$, the concentration at the point closest to the surface plummeted to about half the value of the slurry bulk concentration. Figure 15 corroborates the inability of the 4-in.-diameter impeller to maintain acceptable levels of homogeneity at such a low rotational speed. The time-dependent oscillating concentration distribution indicates that, in this case, the uniform mixing process will never be achieved. 


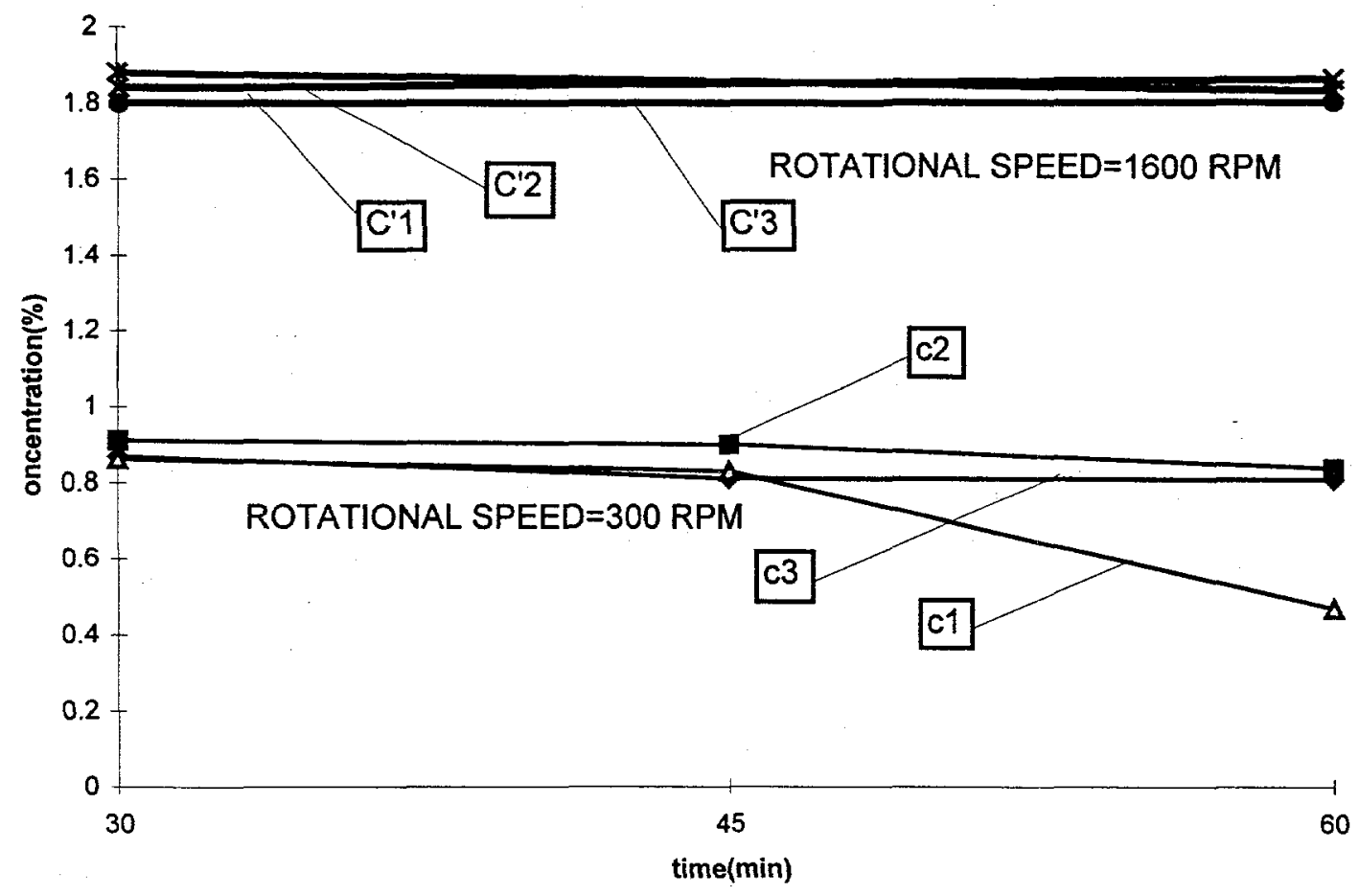

Figure 14. Concentration profile under rotational speeds of 300 and $1600 \mathrm{rpm}$ with a 4in.-dimameter impeller. C'1, C'2, and C'3 indicate the concentration at $49.5 \mathrm{~cm}$ (closest to the surface), $31.25 \mathrm{~cm}$, and $13 \mathrm{~cm}$ (closest to the bottom), respectively. The same notation applies for $\mathrm{c1}, \mathrm{c2}$ and $\mathrm{c3}$.

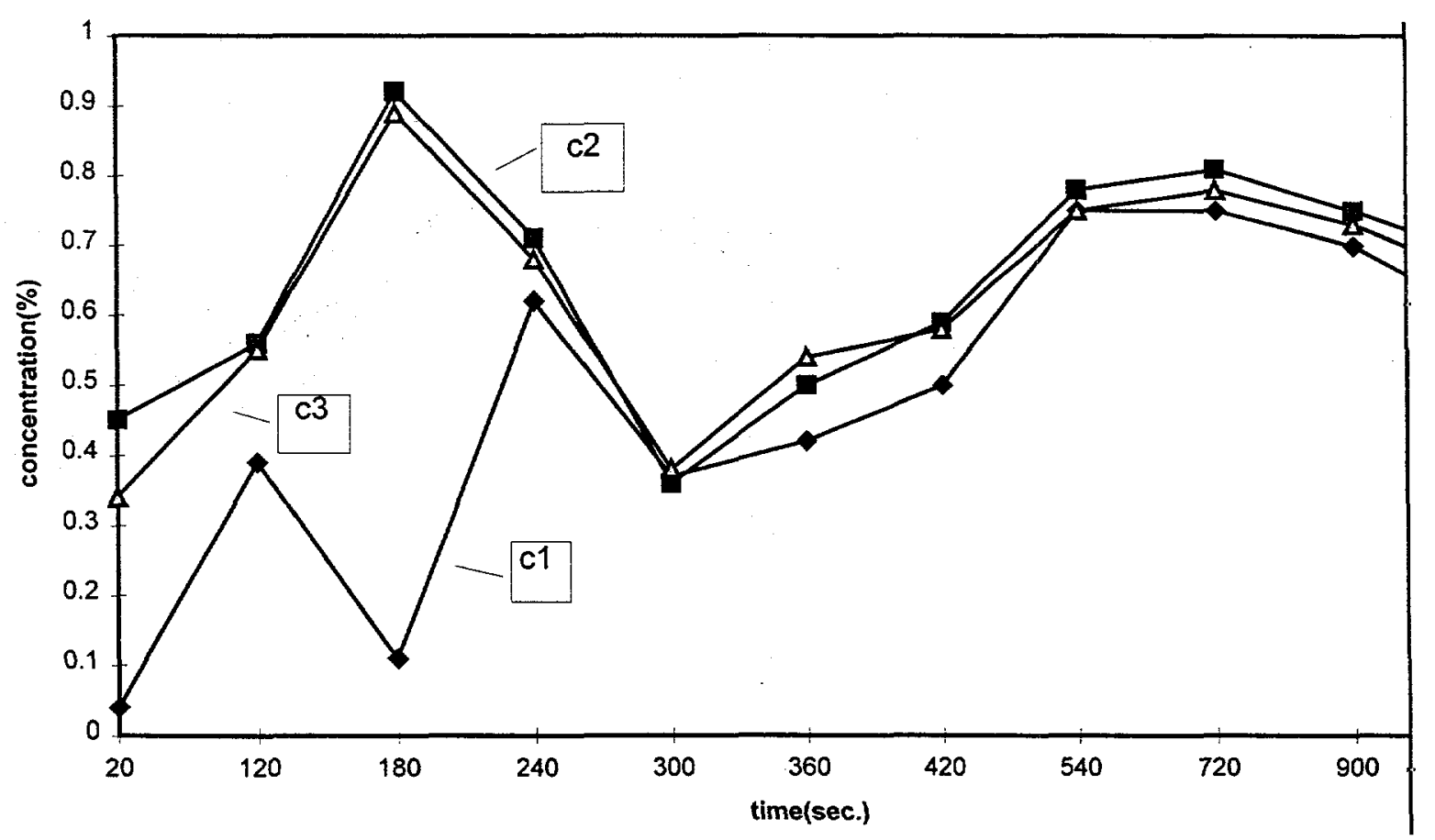

Figure 15. Performance of the 4-in.-diameter impeller at the rotational speed of $300 \mathrm{rpm}$. Homogeneity was never achieved with this small impeller at this speed. 
Extensive experiments were conducted to determine the effect of sampling tube size and sampling speed on the measurement of solids concentration profiles in the vertical direction in the mixing tank with a 6-inch-diameter down axial flow impeller. Two sampling tubes of 0.25 -in. ID and 0.375 -in. ID were used to withdraw samples at different vertical locations in the mixing tank.

For slurry I of a bulk concentration of $5 \%$ by weight, the experiments were conducted under impeller speeds of $200 \mathrm{rpm}$ and $550 \mathrm{rpm}$. Figures 16 and 17 show the measured solids concentration profiles at an impeller speed of $200 \mathrm{rpm}$ with sampling tubes of 0.25 -in. ID and 0.375 -in. ID, respectively. We discovered that the lowest sampling speed $(0.02105 \mathrm{~m} / \mathrm{s})$ resulted in a concentration reading approximately $76 \%$ lower than the slurry's bulk concentration. This is because the low sampling speed resulted in a considerable amount of solids, especially the ferric oxide particles, settling in the tubing on its way to the collecting container. In general, when the sampling speed is increased, the measured solids concentration increases. As is evident in Figures 16 and 17, if the sampling speed is not too low (for example, $0.3157 \mathrm{~m} / \mathrm{s}$ ), the larger sampling tube can generate a higher solids concentration, which is closer to the slurry's bulk concentration. Figures 18 and 19 present similar results of solids concentration profiles at an impeller speed of $550 \mathrm{rpm}$ with sampling tubes of 0.25 -in. ID and 0.375 -in. ID, respectively. Based on the slurry homogeneity within the investigated parameter ranges, we recommend that, to obtain representative sampling results, larger diameter sampling tubes and higher sampling speeds be used whenever possible.

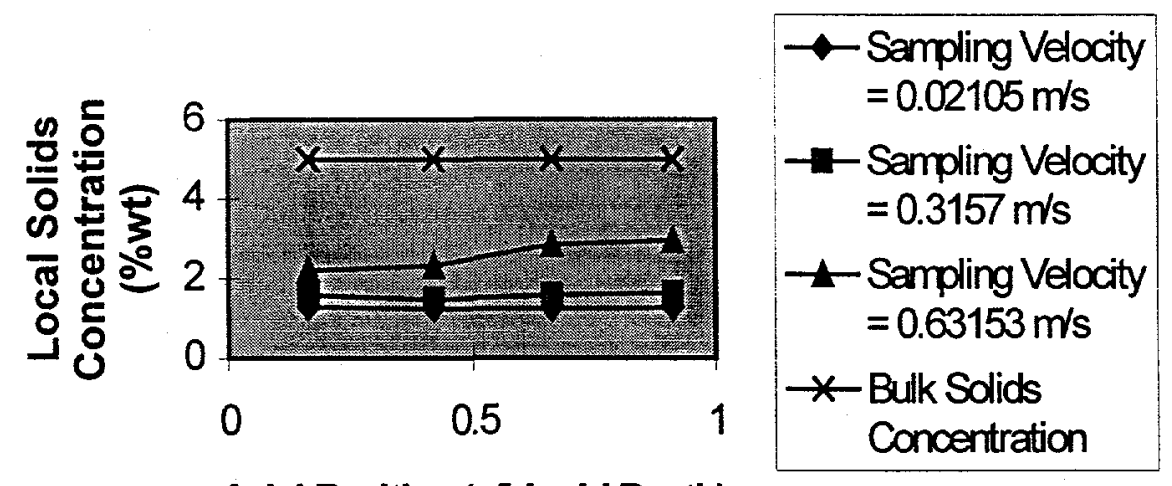

Axial Position (y/Liquid Depth)

Figure 16. Measured local solids concentrations of slurry $I$ at different axial positions with a 0.25 -in. ID sampling tube at an impeller speed of $200 \mathrm{rpm}$. Electrical power consumed is $60 \mathrm{~W}$. Liquid depth is $0.55 \mathrm{~m}$. 

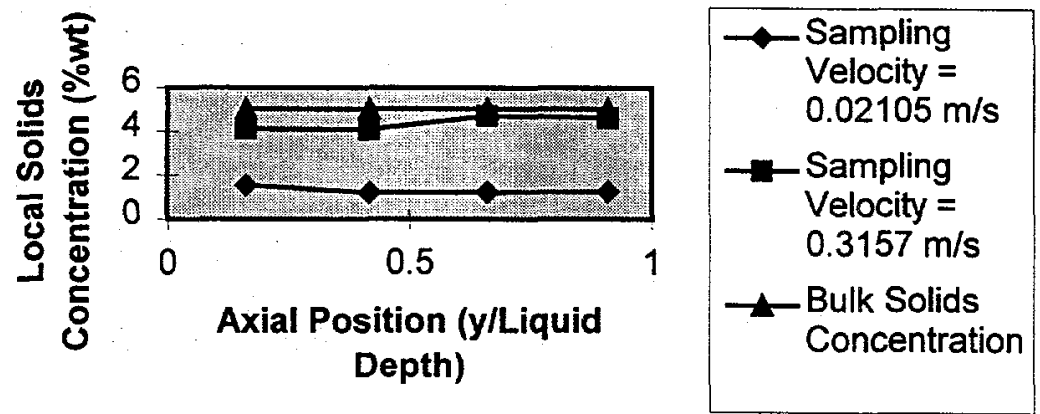

Figure 17. Measured local solids concentrations of slurry $I$ at different axial positions with a 0.375 -in. ID sampling tube at an impeller speed of $200 \mathrm{rpm}$. Electrical power consumed is $60 \mathrm{~W}$. Liquid depth is $0.55 \mathrm{~m}$.

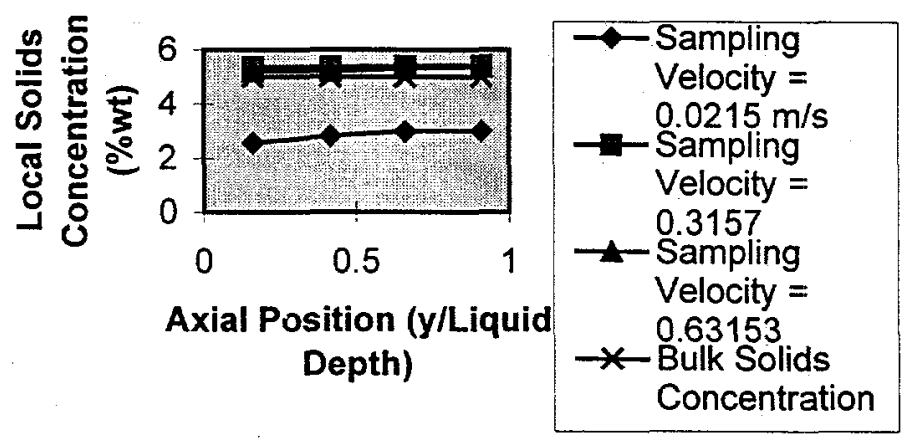

Figure 18. Measured local solids concentrations of slurry $I$ at different axial positions with a 0.25 -in. ID sampling tube at an impeller speed of $550 \mathrm{rpm}$. Electrical power consumed is $60 \mathrm{~W}$. Liquid depth is $0.55 \mathrm{~m}$.

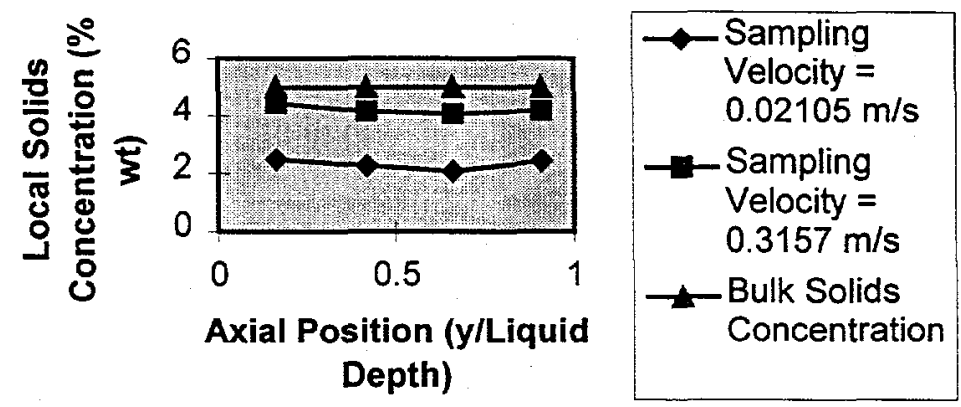

Figure 19. Measured local solids concentrations of slurry I at different axial positions with a 0.375 -in. ID sampling tube at an impeller speed of $550 \mathrm{rpm}$. Electrical power consumed is $60 \mathrm{~W}$. Liquid depth is $0.55 \mathrm{~m}$. 
As a comparison, the slurry II's typical results of solids concentration are provided in Figures 20 22. All the solids concentrations in Figures 20-22 were measured with a 0.25-in.-diameter sampling tube. The slurry's bulk concentration in Figures 20 and 21 is $5 \%$ by wt also. The impellers' speeds in Figures 20,21, and 22 are $500 \mathrm{rpm}, 600 \mathrm{rpm}$, and $400 \mathrm{rpm}$, respectively. And the impellers' sizes in Figures 20, 21, and 22 are 6-in., 6-in., and 8-in., respectively. As can be seen in Figures 20-22, the variation phenomena of solids concentration distribution with slurry II due to the change of sampling velocity is very similar to that with slurry $I$.

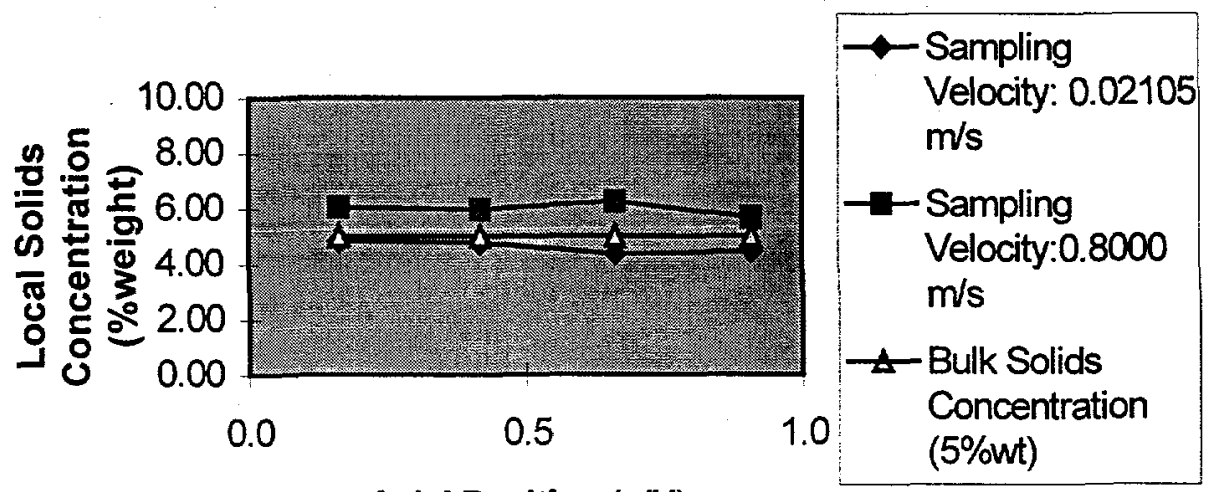

Axial Position (y/H)

Figure 20. Measured local solids concentration of slurry II at different axial positions for a 6-in.-diameter impeller (axial-flow, pump direction: down) rotating at $500 \mathrm{rpm}$. Electrical power consumed: $48 \mathrm{~W}$. Liquid level is $0.55 \mathrm{~m}$.

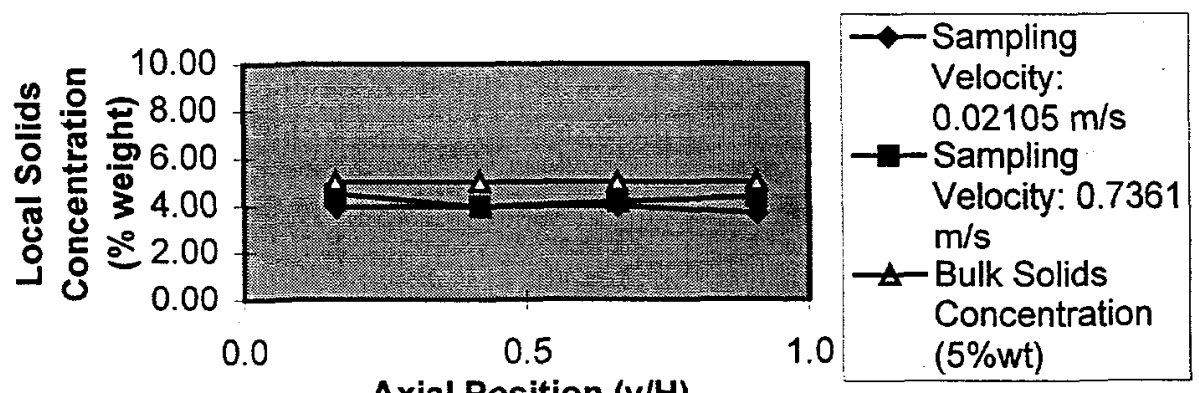

Figure 21. Measured local solids concentration of slurry II at different axial positions for a 6-in.-diameter impeller (axial-flow, pump direction: down) rotating at $600 \mathrm{rpm}$. Electrical power consumed: 60 $w$. Liquid level is $0.55 \mathrm{~m}$. 


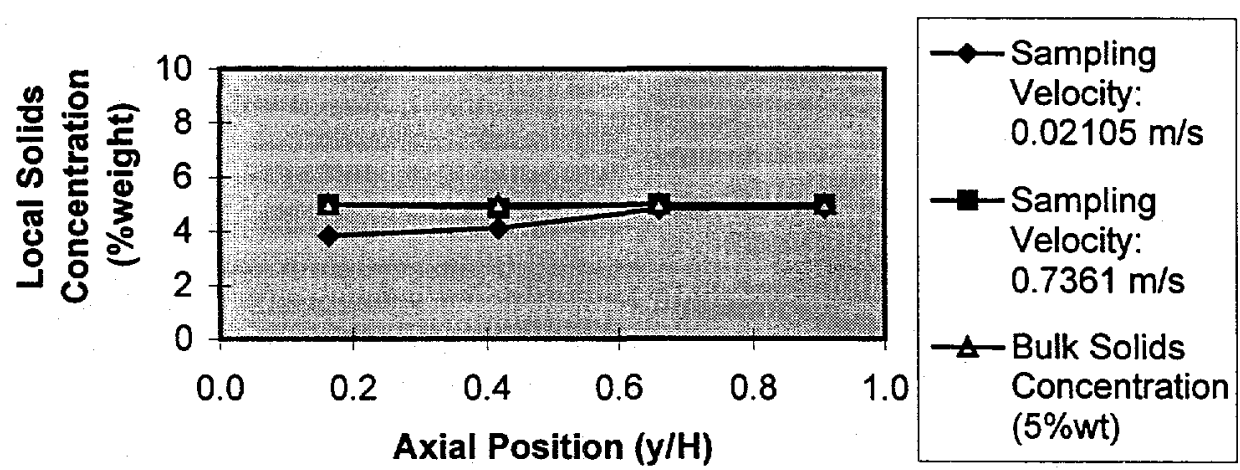

Figure 22. Measured local solids concentration of slurry II at different axial positions for an 8-in.-diameter impeller (axial-flow, pump direction: down) rotating at $400 \mathrm{rpm}$. Electrical power consumed: $129 \mathrm{~W}$. Liquid level is $0.55 \mathrm{~m}$.

\subsection{SLURRY VELOCITY FIELDS}

The results of the slurry flow during the tank mixing process were obtained using numerical methods. One of the examined tanks has a 6-in. impeller rotating at a speed of $500 \mathrm{rpm}$. In this case, the flow in the mixing tank is within the turbulent regime. Figures 23-26 provide some of our typical numerical results. Figure 23 shows the vector field of axial velocity on a vertical plane located in the midway between two successive baffles. Figure 24 shows the vector field of velocity magnitude on the same plane as in Figure 23. Figure 25 shows the vector field of velocity magnitude on a horizontal plane that passes the center of the impeller, and Figure 26 shows the vector field of velocity magnitude on a plane at a distance of $0.5 \mathrm{~m}$ from the bottom of the tank. Figure 27 shows the grid applied in the numerical model on a circular section with the grid location corresponding to the radial position of one of the sampling tubes in the experiments. Figure 28 gives the vertical velocity vectors on the section shown in Figure 27. These results give an indication of the velocity at which the sampling pumps must be set to obtain representative samples of solids concentration. They also provide guidance for the arrangement of the sampling probes in both axial and radial directions in the tank mixing experiments.

Within the investigated parameter ranges, the flow patterns in the mixing tank remain similar under different operating conditions. In most of the cases, the major difference between different cases is the velocity magnitude and the turbulence level in the tank. The higher the impeller's rotational speed, the higher the turbulence level. The complex flow patterns identified in certain areas, especially the areas around the impeller, must be taken into account when detailed information is required for the design and monitoring of the tank mixing process.

Although several numerical techniques have been employed for the numerical simulation of the multiphase flows in the mixing tank, extreme difficulties have been encountered to reach stable results. More computational results will be reported in next year's reports. 


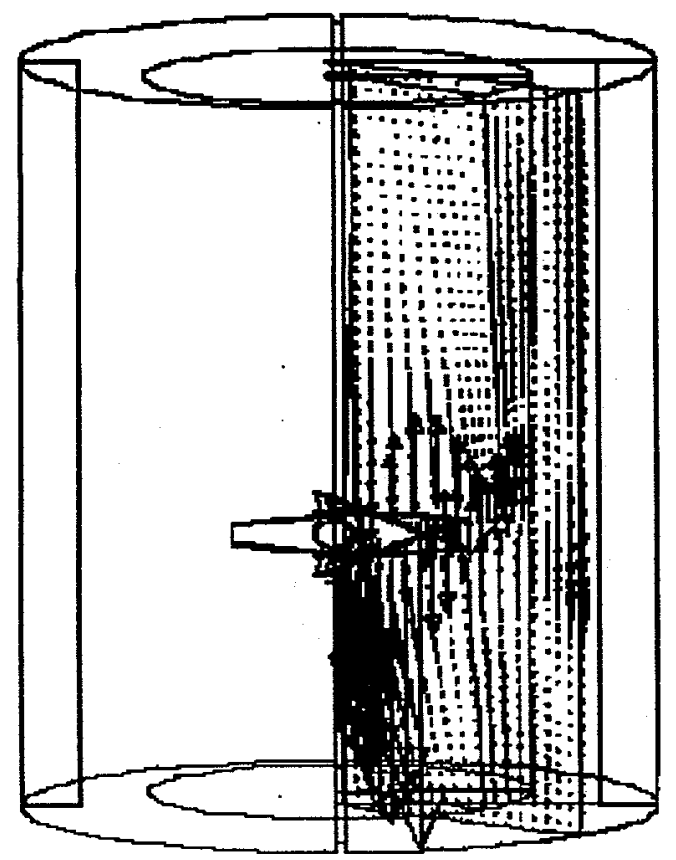

Figure 23. Vector field of axial velocity on a vertical plane located in the midway between two successive baffles.

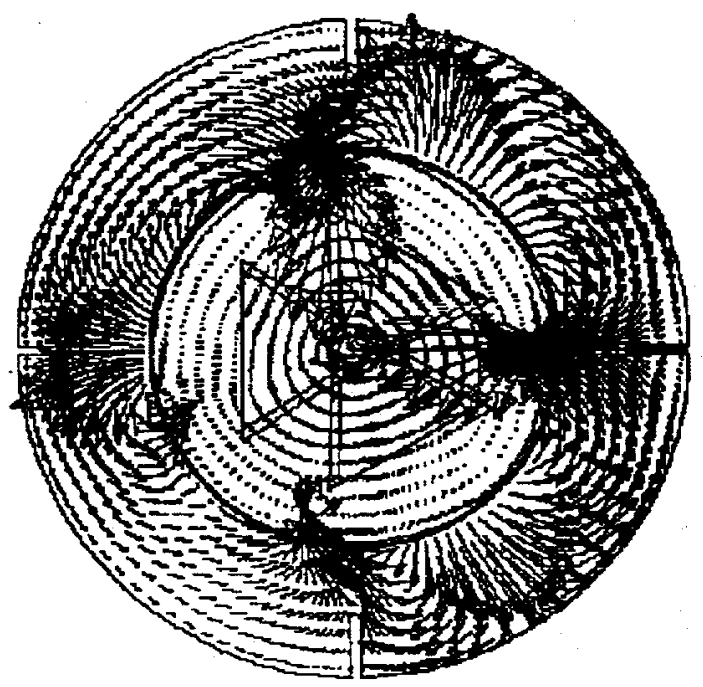

Figure 25. Vector field of velocity magnitude on a horizontal plane which passes the center of impeller.

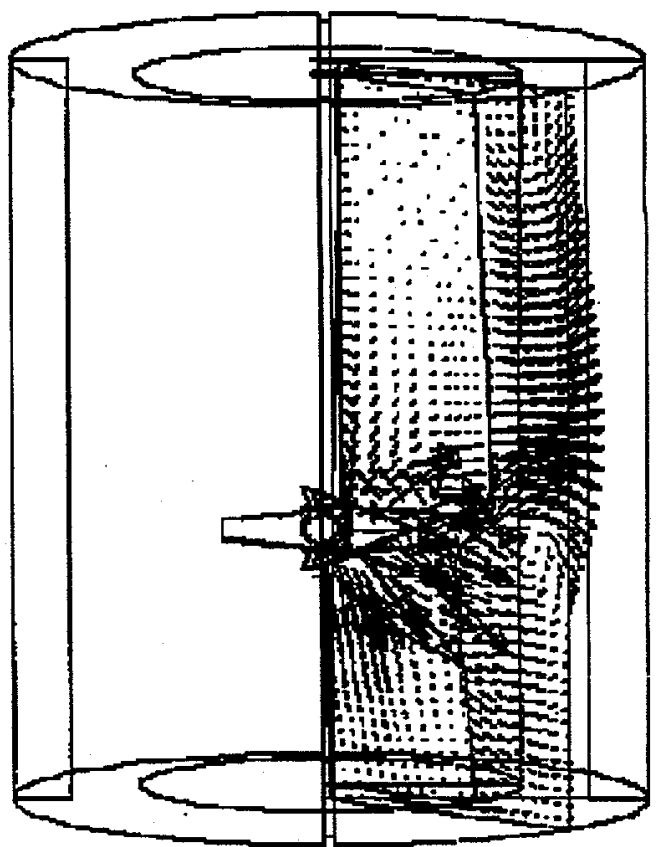

Figure 24. Vector field of velocity magnitude on a vertical plane located in the midway between two successive baffles.

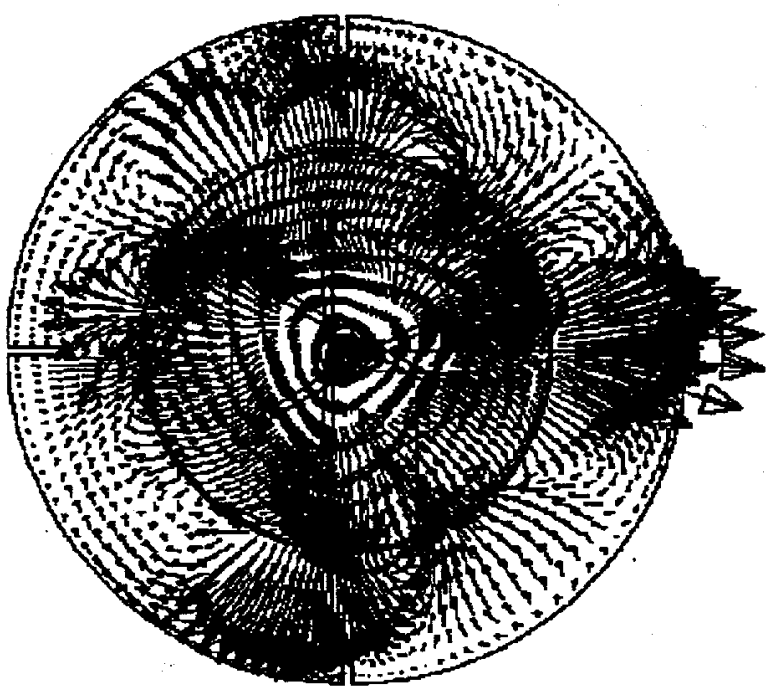

Figure 26. Vector field of velocity magnitude on a plane at a distance of $0.5 \mathrm{~m}$ from the bottom of the tank. 


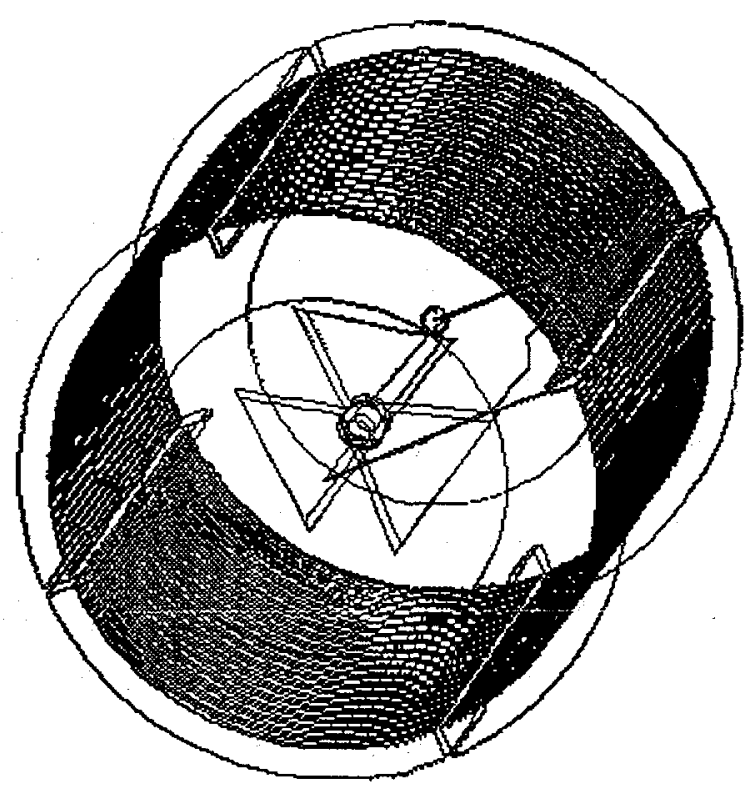

Figure 27. Grid used in the numerical model on a circular section on which the sampling tubes were placed in experiments.

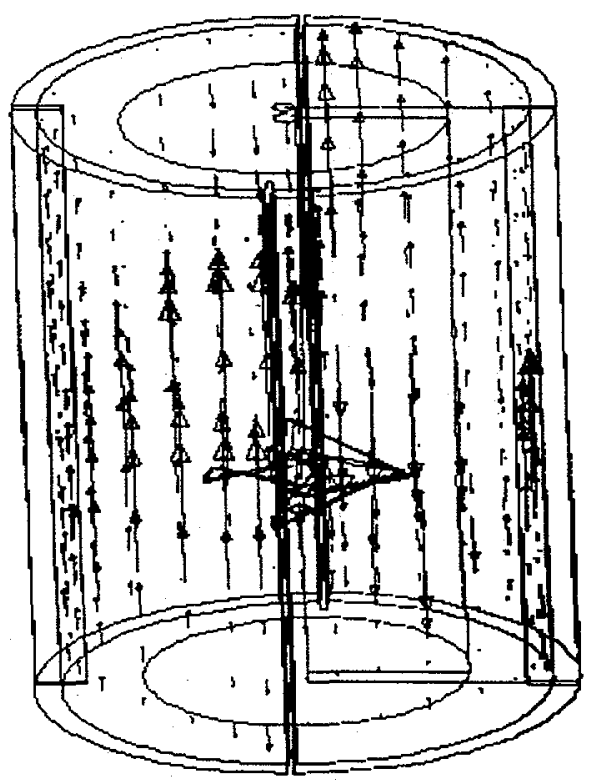

Figure 28. Vertical velocity vector field on the circular section shown in Figure 27. 


\subsection{CONCLUSIONS}

With the slurry simulants prepared in house, the tank batch mixing and sampling processes have been investigated within wide parameter ranges both experimentally and numerically. These investigations were aimed at the applications of the mixing and sampling processes in DWPF vitrification melter feeds. The major parameters investigated in this study include mixer power consumption, mixing time to reach slurry uniformity, slurry type, solids concentration, impeller type, impeller size, impeller rotating speed, sampling tube size, and sampling velocity, etc.

Through this investigation, it was found that, although there are many factors that can affect the tank mixing quality, the mixing homogeneity can be well established by a proper selection of the impeller's rotational speed and impeller size. The following are the present study's major conclusions for the application of the mixing and sampling techniques associated with a batch tank:

- The impeller's power consumption depends primarily on the impeller's rotational speed and size. With different kinds of slurries of close solids concentration, the power consumption could be at the same level with an appropriate impeller.

- Tank mixing process at lower impeller rotational speed can be oscillatory and may never reach uniform mixing quality. To reach steady state homogeneity of the tank mixing, the impeller's speed must be high enough.

- To collect representative sampling results, larger diameter sampling tubes and higher sampling speeds should be used for the tank mixing process whenever possible. In most cases, the relative sampling results at different sampling positions are acceptable for the determination of the mixing status.

- Slurry flows in the mixing process have been revealed to be very complex at different areas in the tanks. This has to be considered when improving the design of a mixing system and when specifying the sampling speed and sampling probe locations. 


\subsection{PLANNED FY98 ACTIVITIES}

The activities planned for FY98 will include both experimental and numerical investigations on the mixing, settling, and pipe plugging phenomena in waste transfer lines. The experimental study of the pipe plugging phenomenon in particular will be addressed. The tank mixing research will be continued, with its primary background being the mixing process associated with pipe plugging. The following is a list of major tasks to be performed in FY98:

Task 1. Research on existing mixing, settling, and pipe plugging/unplugging technologies.

The problems occurring during the application of these technologies in the waste transfer pipelines will be emphasized.

Task 2. Modification and construction of the mixing experimental setup.

The setup will include a batch mixing tank system, an in-line mixer, and a pipeline system for pipe plugging testing.

Task 3. Identification of waste simulants to be used in the experiments.

Slurries similar to those used at DOE sites will be used. Gelation and cooling salt solutions may also be examined.

Task 4. Experimental investigations of the mixing process.

The configurations to be investigated include batch mixing tank, continuous flow pipeline, and inline mixer enhanced system.

Task 5. Experimental investigations of settling and pipe-plugging behaviors.

This will be the major part of FY98's research activity. Extensive experiments will be carried out to determine the settling, pipe plugging and unplugging characteristics in the pipeline system.

Task 6. Development of an efficient sampling system.

This is important to both the mixing process and the pipe plugging problem.

Task 7. Numerical modeling of mixing and settling process.

This will be an extensive parametric study and will be a supplement to the data obtained from the experimental measurements. 


\subsection{REFERENCES}

Barresi, A. and Baldi, G., 1987, Solid dispersion in an agitated vessel, Chemical Engineering Science, Vol. 42, No. 12, pp. 2949-2956.

Dennis, F., Ramsey, A., Jansten, C., Brown, K., 1990, Control of Radioactive Waste Glass Melters: I, Preliminary General Limits at Savannah River, Journal of the American Ceramic Society, Vol. 73, No. 10, pp. 2896-2902.

Gumby, T. R., 1990, Slurry mixing with impellers: Part 1, Theory and previous research, Journal of Agricultural Engineering Research, Vol. 45, pp. 157-173.

Herndl, G. and Mersmann, A. B., 1981, Fluid dynamics and mass-transfer in stirred suspensions, Chemical Engineering Communications, Vol. 13, pp. 23-37.

Landon, L.F., 1994, Task Assignment Rheology Control-DWPF Melter Feed Preparation Processes, WSRC-RP-92-1421, Rev. 1, Westinghouse Savannah River Technology Center, Aiken, SC.

MacTaggart, R. S., Nasr-El-Din, H.A. and Masliyah, J. H., 1993, Sample withdrawal from a slurry mixing tank, Vol. 48, No.5, pp. 921-931.

Magelli, F., Fajner, D., Nocentini, M. and Pasquali, 1990, Solid distribution in vessels stirred with multiple impellers, Chemical Engineering, Vol. 45, No. 3, pp. 615-625.

Mao, F. and Ebadian, M.A., 1997, Rheological Properties of Defense Waste Processing Facility (DWPF) Melter Feeds, Final Report, Hemispheric Center for Environmental Technology, Miami.

Marek, J.C., 1994, Baseline Task Technical Plan to Develop Technical Bases for Rheology Control of DWFP Melter Feed Preparation Process, WSRC-RP-94-558, Rev. 0, Westinghouse Savannah River Technology Center, Aiken, SC.

Mei, R., Adrian, R. J. and Hanratty, T. J., 1997, Turbulent dispersion of heavy particles with nonlinear drag, Journal of Fluids Engineering, Vol. 119, pp. 170-179.

Nasr-El-Din, H. A., MacTaggart, R. S. and Masliyah, J. H., 1996, Local solids concentration measurement in a slurry mixing tank, Chemical Engineering Science, Vol. 51, No. 8, pp. 1209-1220.

Patankar, S. V., 1980, Numerical Heat Transfer and Fluid Flow, McGraw-Hill, New York.

Patankar, S.V. and Spalding, D. B., 1972, A calculation procedure for heat, mass and momentum transfer in three-dimensional parabolic flows, International Journal of Heat and Mass Transfer, Vol. 15, pp. 1787-1806.

Rasteiro, M. G., Figueiredo, M.M. and Freire, C., 1994, Modelling slurry mixing tanks, Advanced Powder Technol., Vol. 5, No. 1, pp. 1-14. 
Syamlal, M., 1987, The Particle-Particle Drag Term in a Multiparticle Model of Fluidization, Topical Report, DOE/MC/21353-2373, NTIS/DE87006500, National Technical Information Service, Springfield, VA.

Syamlal, M., Rogers, W., and O'Brien, T. J., 1993, MFIX Documentation: Volume 1, Theory Guide, DOE/METC-9411004, NTIS/DE9400087, National Technical Information Service, Springfield, VA.

Tojo, K. and Miyanami, K., 1982, Solids suspension in mixing tanks, Ind. Eng. Chem. Fundam., Vol. 21, pp. 214-220.

Yamazaki, H., Tojo, K. and Miyanami, K., 1986, Concentration profiles of solids suspended in a stirred tank, Powder Technology, Vol. 48, pp. 205-216. 